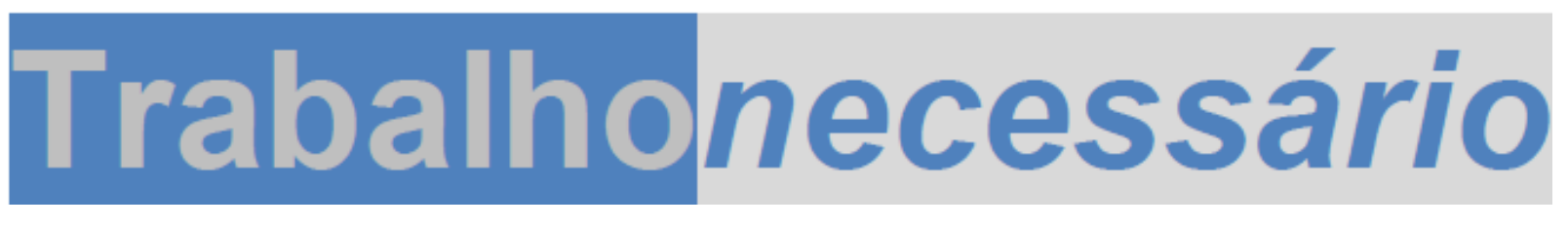

Issn: 1808 - 799X

ano $11, \mathrm{n}=16-2013$

\title{
A EDUCAÇÃO PROFISSIONAL NO CONTEXTO DA REENGENHARIA INSTITUCIONAL DA POLÍTICA PÚBLICA DE TRABALHO, QUALIFICAÇÃO E GERAÇÃO DE RENDA: novos e velhos mecanismos de manutenção da hegemonia burguesa no Governo FHC
}

\begin{abstract}
José dos Santos Souza ${ }^{1}$
Resumo: O objetivo deste artigo é explicitar os fundamentos políticos e ideológicos que determinaram a mais recente reforma da educação profissional no Brasil. Para isto, aborda as ações do governo Fernando Henrique Cardoso no campo da educação profissional como parte de uma articulação muito mais ampla que visava estruturar a nova engenharia institucional para o desenvolvimento da política pública de trabalho, qualificação e geração de emprego e renda no Brasil dos anos 1990. Tomando como referência sócio histórica a crise estrutural do capital e a consequente reestruturação do trabalho, da produção e dos mecanismos de mediação do conflito de classes, a análise conclui que os esforços governamentais para a qualificação permanente da força de trabalho tem o mérito o potencial pedagógico de educar grandes contingentes de trabalhadores pobres para o consenso em torno da ideologia da empregabilidade e do empreendedorismo. Em lugar de inserir trabalhadores pobres no mercado de trabalho, a política pública de trabalho, qualificação e geração de emprego e renda tem como maior mérito a mediação do conflito de classe, diluindo a pressão política dos trabalhadores sobre o poder público e o empresariado.
\end{abstract}

Palavras-Chave: Trabalho; Qualificação; Política Pública; Educação Profissional.

Abstract: The purpose of this article is to outline the political and ideological foundations that determined the most recent Brazilian vocational education reform.

\footnotetext{
${ }^{1}$ Doutor em Sociologia pela UNICAMP, professor adjunto do Departamento de Educação e Sociedade do Instituto Multidisciplinar da Universidade Federal Rural do Rio de Janeiro, Brasil. Atua como docente no Programa de Pós-Graduação em Educação, Contextos Contemporâneos e Demandas Populares (PPGEduc) e no Programa de Pós-Graduação em Educação Agrícola (PPGEA). Atualmente é coordenador do Grupo de Pesquisa Sobre Trabalho, Política e Sociedade (GTPS). Endereço Eletrônico: jsantos@ufrri.br
}

TrabalhoNecessário - www.uff.br/trabalhonecessario; Ano 11, № 16/2013. 


\section{Trabalhonecessário}

Issn: 1808 - 799X

ano 11, no $16-2013$

For this, discusses the actions of the Fernando Henrique Cardoso government in the field of professional education as part of a much broader articulation aimed at structuring the new institutional engineering for the development of public policy working, qualification and generation employment and income in Brazil of 1990s. Based on the structural crisis of capital as social and historical reference, the article analyzes the restructuring of labor, of production and of mediation mechanisms of class conflict. The concludes that government efforts to qualifying workforce has the merit to educate large numbers of poor workers at consensus on the ideology of employability and entrepreneurship. Instead of entering poor workers in the labor market, the public policy of working, qualification and employment generation and income has the greatest merit the class conflict mediation, diluting the workers' pressure on the government and entrepreneurs.

Keywords: Work; Qualification; Public Policy, Professional Education.

Como parte de uma investigação mais ampla ${ }^{2}$, sistematizamos nesse artigo um esforço para explicitar os fundamentos políticos e ideológicos que determinaram a mais recente reforma da educação profissional no Brasil. Para esta análise, tomamos como recorte sócio histórico as ações governamentais empreendidas a partir da segunda metade da década de 1990, quando ocorrem

\footnotetext{
${ }^{2}$ A investigação mais ampla a que nos referimos se trata do Projeto de Pesquisa intitulado "Trabalho, Juventude e Educação Profissional: a pedagogia política dos programas governamentais de inclusão jovens no Brasil", desenvolvido no âmbito do Grupo de Pesquisas Sobre Trabalho, Política e Sociedade (GTPS) do Departamento de Educação e Sociedade da UFRRJ, no período de 2010 a 2012. Esta investigação tinha como objeto de estudo a implantação e desenvolvimento de programas governamentais de inclusão de jovens de 16 a 29 anos, em municípios selecionados da Baixada Fluminense, que se propunham a oferecer aceleração de escolaridade integrada à educação profissional para a população jovem, a saber: o PROEJA, o ProJovem e o CVT. O objetivo dessa investigação era explicitar a pedagogia política renovada inerente à implantação e desenvolvimento desses programas de governo. Em síntese, a investigação conclui que tais programas de governo, mesmo que possam oferecer oportunidades reais de ingresso e permanência no mercado de trabalho a uma parte ínfima da população jovem, em decorrência da formação oferecida, seu principal efeito pedagógico não é esse. O efeito pedagógico mais relevante, embora menos evidente, é educar os jovens trabalhadores para o espírito empreendedor em um mercado de trabalho mais excludente e competitivo. Desse modo, conforma esse segmento populacional à mais recente realidade da classe trabalhadora: marcada pela exclusão social, pela intensificação da precariedade, pela flexibilização do trabalho e da produção, pela desregulamentação dos direitos trabalhistas e pelo desemprego estrutural.
}

TrabalhoNecessário - www.uff.br/trabalhonecessario; Ano 11, № 16/2013. 


\section{Trabalhonecessário}

Issn: 1808 - 799X

ano 11, no $16-2013$

mudanças significativas na política educacional brasileira. Nosso foco analítico são as ações governamentais para ajustar a formação e a qualificação do trabalhador às novas exigências de produtividade e competitividade das empresas.

Para o desenvolvimento da análise aqui apresentada, partimos de três pressupostos básicos: a) de que tais mudanças no campo da educação se inserem no conjunto de ações políticas empreendidas pelo empresariado e pelo Estado para recompor as bases de acumulação de capital corroídas pela crise estrutural da ordem burguesa de produção e reprodução social da vida material; b) as ações objetivas do Estado e do empresariado para ajustar o sistema educacional às novas demandas de produtividade e competitividade das empresas carregam em seu bojo uma pedagogia política renovada capaz de acionar na sociedade civil o consenso em torno do projeto educativo hegemônico, levando parte significativa dos trabalhadores e de suas organizações coletivas ao consentimento ativo diante da implementação desse projeto; c) a reforma da Educação Profissional no Brasil atualiza a concepção burguesa de relação entre formação para o trabalho e formação geral básica, por meio do recrudescimento da Teoria do Capital Humano, do exacerbamento da racionalidade economicista na gestão da qualidade (qualidade total) e da separação sistêmica entre o trabalho educativo da Educação Profissional e 0 da Educação Básica, reconfigurando a dualidade histórica de formação humana no capitalismo - para os trabalhadores, formação para o trabalho; para a classe dominante, formação científica e tecnológica ou filosófica. A partir desses três pressupostos básicos, compreendemos que as ações governamentais empreendidas no Brasil para a reconfiguração da formação humana expressam a estratégia capitalista de, por meio do Estado, a classe dominante empreender a mediação do conflito de classe, diluindo a pressão política dos trabalhadores sobre o poder público e o 


\section{Trabalhonecessário}

Issn: 1808 - 799X

ano 11, no $16-2013$

empresariado, em função dos efeitos deletérios da contrarreforma burguesa sobre o cotidiano da vida social no Brasil a partir dos anos 1990.

Nosso objeto de análise são as ações do governo no campo da educação profissional a partir dos anos 1990, como parte de uma articulação muito mais ampla do capital em âmbito mundial, a fim de estruturar uma nova engenharia institucional para o desenvolvimento de ações governamentais para o trabalho e a produção, para a formação/qualificação profissional e para a geração de emprego e renda. Em observância aos limites desse artigo, limitamos nossa análise às ações do Governo Fernando Henrique Cardoso, por entender que foi a partir desse governo que as reformas mais relevantes nesse sentido foram estruturadas. Isto não significa que os governos subsequentes tenham seguido rumo diverso, tampouco que suas ações foram de importância menor. Trata-se meramente de uma opção que nos permitiu melhor apresentar a análise empreendida.

Resta-nos, ainda, observar que se trata de uma análise qualitativa, de caráter explicativo, que se utiliza da revisão de literatura sobre "trabalho e educação", sobre "políticas públicas de trabalho e renda" e, mais especificamente, sobre "reforma da educação profissional no Brasil"; utiliza-se também de análise de outras fontes secundárias, tais como documentos governamentais e a legislação educacional vigente.

Para a exposição da análise, optamos por abordar a crise estrutural do capital e a contrarreforma burguesa para reconfigurar seus mecanismos de mediação do conflito de classes e recompor as bases de acumulação da riqueza. Posteriormente, buscaremos explicar como essa ofensiva do capital determinou a reforma da educação profissional brasileira nos anos 1990, com o intuito de ajustar o sistema educacional brasileiro às novas demandas de produtividades e competitividade das empresas no mercado mundializado, bem como de educar a sociedade civil para o consenso em torno do projeto educativo hegemônico. Por

TrabalhoNecessário - www.uff.br/trabalhonecessario; Ano 11, № 16/2013. 


\section{Trabalhonecessário}

Issn: 1808 - 799X

ano 11, no $16-2013$

fim, trataremos das ações do governo Fernando Henrique Cardoso, indicando como suas ações se inserem de modo coerente nesse contexto. Vejamos.

A crise estrutural do capital vivenciada na atualidade poderia ser traduzida como a crise do modelo de desenvolvimento taylorista-fordista; e seu significado mais profundo é a evidência e a confirmação da tese marxista da queda tendencial das taxas de lucro como uma marca inerente ao processo de desenvolvimento do capital. Em decorrência dessa tendência, a luta visceral do capital para recompor suas bases de acumulação deflagra outras duas tendências que poderiam ser apontadas como dimensões de sua crise estrutural: a depreciação do valor de uso das mercadorias e a incontrolabilidade do sistema de metabolismo social do capital (Antunes, 2000: p. 31).

Entretanto, os períodos de crise e, em decorrência, os períodos cada vez mais tênues de estabilidade do capital são fenômenos que se expressam no cotidiano social em forma de um conjunto complexo de mudanças permanentes no processo de desenvolvimento do capital. Tais mudanças abrangem, desde as forças produtivas e as relações de produção, até as relações de poder, passando pelo imaginário social, a cultura, a arte, a religião, etc. A amplitude multidimensional desse processo de recomposição do capital constitui, em determinados momentos históricos, uma unidade contraditória e discordante entre o econômico e o político, entre a natureza e o espírito, unidade dos contrários e dos distintos, ao que Gramsci chamou de bloco histórico, ou seja, estágio em que a relação entre governantes e governados, mediatizada pelos intelectuais, estabelece-se graças a uma ação orgânica, possibilitada pela hegemonia, propiciando a troca de elementos individuais entre governantes e governados, entre dirigentes e dirigidos, consolidando-se assim o sentimento de unidade entre intelectuais e massa, entre filosofia e senso comum, de onde emana a vida do conjunto - o bloco histórico (Gramsci, 1999 e 2000; Portelli, 1997).

TrabalhoNecessário - www.uff.br/trabalhonecessario; Ano 11, № 16/2013. 


\section{Trabalhonecessário}

Issn: 1808 - 799X

ano 11, no $16-2013$

Em resposta à crise estrutural do capital, seus intelectuais orgânicos mantêm-se na superfície do problema, agindo na dimensão fenomênica da crise, sem atingir os pilares essenciais do modo de produção e reprodução social da vida material. A preocupação central desses intelectuais é reestruturar o regime de acumulação taylorista-fordista em busca de condições de flexibilidade do trabalho e da produção, bem como romper com o modo de regulação social próprio do Estado de Bem-Estar Social e redefinir o papel do Estado, especialmente no que concerne às questões sociais, enxugando a aparelhagem estatal, com vistas no controle do déficit público, uma marca registrada do esgotamento desse modelo de regulação social. Assim o capital procura implantar um novo industrialismo, uma forma renovada de metabolismo social, numa luta visceral de recomposição de suas bases de acumulação, utilizando-se de novos e velhos mecanismos de gestão do trabalho e da produção.

Assim, o esgotamento do modelo de desenvolvimento fundado no pós II Guerra Mundial, somado ao acúmulo de inovações tecnológicas no campo da microeletrônica e da informática, e ao avanço das conquistas políticas da própria classe trabalhadora, constituíram as condições objetivas da empreitada do capital no nível mundial para recompor suas bases de acumulação e implantar novas modalidades de produção e de mediação do conflito capital/trabalho. A expressão política dessa recomposição do capital tem configurado uma verdadeira redefinição do papel do Estado e o fomento de uma "nova" cultura cidadã fundada no individualismo e na competitividade, regulada pela lógica mercadológica, compondo a formação de um novo bloco histórico, um novo industrialismo, um novo tipo de metabolismo do capital.

Entretanto, na medida em que avança a maquinaria, - como necessidade cada vez mais premente para a manutenção e/ou ampliação das taxas de maisvalia relativa - tornam-se cada vez mais frequentes as iniciativas de formação e qualificação do trabalhador para atender as novas demandas ocupacionais. Para

TrabalhoNecessário - www.uff.br/trabalhonecessario; Ano 11, № 16/2013. 


\section{Trabalhonecessário}

Issn: 1808 - 799X

ano 11, no $16-2013$

garantir suas condições de acumulação, a burguesia se vê obrigada a suplantar constantemente os limites por ela mesma impostos à socialização do conhecimento na sociedade de classes. Eis aqui uma das contradições inerentes ao processo de valorização do capital no que concerne à educação.

Cônscia dos riscos políticos e ideológicos dessa contradição, a burguesia busca impor limites ao processo de formação/qualificação profissional e social do trabalhador coletivo. Atenta para o fato de que a ampliação do conhecimento científico e tecnológico necessário às suas necessidades de acumulação constitui um elemento determinante do aumento da demanda dos trabalhadores por educação, a burguesia procura redefinir sua política de formação/qualificação profissional. Esta redefinição tem como objetivo limitar o acesso ao conhecimento técnico-científico a um seleto contingente da força de trabalho, enquanto a grande maioria é atendida por um tipo de qualificação profissional fragmentada, em caráter de treinamento. Embora este tipo de qualificação fragmentada não prepare uma parcela significativa da força de trabalho para apropriar-se da ciência e da tecnologia aplicada na produção, pelo menos tem o efeito de conformação ético-política deste segmento da força de trabalho na nova conjuntura excludente do mercado de trabalho. Funciona como uma espécie de educação para o desemprego, na medida em que prepara parcelas significativas da força de trabalho para permanecerem à margem do mercado formal de trabalho, contentadas com subempregos, trabalhos precários, "bicos" ou trabalhos temporários. Mais que isto, prepara estas parcelas da classe trabalhadora para encararem com naturalidade tal situação e conformar-se a ela.

Desse modo, além de atender à necessidade estrutural do capitalismo, a burguesia ainda consegue com tal medida conformar esse imenso contingente de trabalhadores no leito de mudanças substanciais por que passa o cotidiano das empresas, bem como o cotidiano social. Neste aspecto superestrutural, as ações burguesas no campo da política de formação/qualificação profissional promovem

TrabalhoNecessário - www.uff.br/trabalhonecessario; Ano 11, № 16/2013. 


\section{Trabalhonecessário}

Issn: 1808 - 799X

ano 11, no $16-2013$

um sentimento tal que faz os indivíduos sentirem-se contemplados em suas demandas individuais de acumulação de capital humano, apesar de, possivelmente, jamais virem a conseguir colocação no mercado de trabalho em decorrência da formação/qualificação recebida. Isto significa que, mesmo que possamos vivenciar uma ampliação considerável da oferta de serviços educacionais voltados para a formação e qualificação do trabalhador, de modo geral, esta oferta significa muito mais um mecanismo de mediação do conflito de classe no campo da luta pelo acesso ao conhecimento científico e tecnológico do que um instrumento de formação/qualificação profissional propriamente dita.

O discurso do Governo Brasileiro ao final dos anos 1990, quando passou a denominar seu projeto de formação e qualificação do trabalhador coletivo de "Plano de Qualificação Profissional e Social", expressa muito bem esse processo, ou seja: para um seleto contingente da força de trabalho, a qualificação profissional; para a grande maioria, basta a qualificação social. Claro que esta entendida aqui como um tipo de formação/qualificação para garantir competências individuais para a conformação ético-política do sujeito à nova realidade das relações de produção e da necessária reconfiguração da relação entre Estado e sociedade civil.

Entretanto, não se pode negar que nesse processo está evidenciada a contradição básica com a qual a burguesia se vê ameaçada cada vez mais, qual seja: verbalizar a necessidade de ampliar as ofertas de formação/qualificação profissional para a classe trabalhadora - muitas vezes unindo-se a ela, sob a mediação do Estado, para o atendimento desta necessidade - e, ao mesmo tempo, ser obrigada a controlar o acesso ao conhecimento científico e tecnológico aplicado produtivamente. É neste aspecto que o binômio industrialismo/ democracia $^{3}$ pode consubstanciar-se em favor da classe trabalhadora, na medida

\footnotetext{
${ }^{3}$ Utilizamo-nos de "binômio Industrialismo/democracia" para fazer referência à unidade emanada da relação entre o processo de avanço da maquinofatura e das relações de produção, de um lado,
}

TrabalhoNecessário - www.uff.br/trabalhonecessario; Ano 11, № 16/2013. 


\section{Trabalhonecessário}

Issn: 1808 - 799X

ano 11, no $16-2013$

em que evidencia esta contradição e the abre novas possibilidades de organização e luta pelo alargamento dos limites impostos pela burguesia ao acesso ao conhecimento. ${ }^{4}$

Em síntese, poderíamos afirmar que as contradições inerentes às políticas educacionais na sociedade de classes são determinadas pelo binômio industrialismo/democracia e constituem, em si, um campo de luta entre capital e trabalho. Na dimensão estrutural, a disputa capital/trabalho se dá neste campo por meio da luta pelo acesso ao conhecimento científico e tecnológico necessário à produção. Na dimensão superestrutural, esta disputa se trava na concepção e nas estratégias de implementação da política de educação básica e profissional.

Neste contexto se insere a reforma da Educação Profissional no Brasil, ainda em curso. Há muita coisa escrita sobre este tema ${ }^{5}$. Entretanto, a maioria dos trabalhos limita-se à mera exposição das ações e formulações da aparelhagem estatal nesse campo, em especial do poder executivo. Outros chegam a abordar as ações e formulações dos trabalhadores organizados acerca da educação ${ }^{6}$. No entanto, muitas destas exposições carecem de uma análise

e o processo de ampliação e aperfeiçoamento dos mecanismos de controle social sobre as decisões estatais, de outro, verificados na história do capitalismo como uma tendência a ele inerente. Tal unidade foi preconizada por Marx (1972) no Manifesto, amplamente explorada por Gramsci (2001) em "Americanismo e Fordismo". No Brasil, Coutinho (1992; 1994; 2000), ao se preocupar em aplicar a teoria gramsciana como instrumento analítico da realidade brasileira contemporânea, bem como Neves (1994), ao buscar fazer o mesmo para a análise da educação brasileira, acabam oferecendo o suporte teórico para essa categoria. A propósito, foi Neves (1994) quem primeiro utilizou o termo "binômio industrialismo/democracia" para fazer referência à unidade entre estrutura e superestrutura no desenvolvimento da ordem burguesa.

4 Ainda assim, mesmo que ocorra tal reconhecimento, de acordo com uma perspectiva revolucionária, seria necessário ainda estabelecer como referência a superação da sociedade de classes e a instauração de um novo modelo social de produção e reprodução da vida material. Sem esta referência, qualquer reconhecimento deste tipo jamais se materializaria em uma ação realmente anticapitalista. Ao contrário, apesar do caráter crítico, manter-se-ia nos limites da ordem social burguesa.

${ }^{5}$ Dentre os diversos trabalhos sobre a reforma da educação profissional, poderíamos destacar o de Manfredi (2002), pela sua amplitude, o que nos permite uma visão bastante abrangente deste processo. Alem deste, poderíamos citar: Kuenzer (1997); Moraes (1988); Oliveira (2001); Santos (2001).

${ }^{6}$ Sobre as ações e formulações dos trabalhadores organizados sobre educação, consultar: Deluiz,

TrabalhoNecessário - www.uff.br/trabalhonecessario; Ano 11, № 16/2013. 


\section{Trabalhonecessário}

Issn: $1808-799 X$

ano 11, no $16-2013$

mais profunda que estabeleça relações entre estas ações e a dinâmica das relações de poder na sociedade. No máximo, estabelecem relações com o processo de reestruturação produtiva e seu consequente aumento da demanda por qualificação da força de trabalho.

É válido mencionar também a existência de um conjunto de estudos disponíveis na bibliografia nacional e internacional, na área da negociação coletiva da formação profissional, que analisam e documentam experiências de incorporação do diálogo social na construção de uma nova institucionalidade da educação profissional. A maioria delas se baseia na experiência européia para interpretar a realidade das relações trabalhistas no Brasil e na América Latina. Essa bibliografia tem tratado de experiências que visam dar respostas às novas condições do mercado de trabalho que demandam um sistema de formação profissional mais flexível, descentralizado, que atenda com qualidade às necessidades de desenvolvimentos econômico e social, de acordo com os limites impostos pelo novo industrialismo. Entretanto, o faz de forma não crítica, desconsiderando o próprio conflito de classe que, contraditoriamente, acredita ser

passível de conformação mediante a colaboração entre os sujeitos coletivos envolvidos ${ }^{7}$.

De acordo com essa visão, o que importa é a indicação da suposta possibilidade de diálogo social entre sujeitos coletivos de interesses antagônicos. Predomina a crença de que os diferentes sujeitos coletivos, cada um

Santana \& Souza (1999). Já em uma linha mais crítica, consultar: Tumolo (1999), Souza (2000 e 2002) e Fidalgo (1999).

7 Ver, por exemplo, Posthuma (2002), que coordenou uma coletânea onde se analisam as experiências de diálogo social no campo da negociação da formação profissional e suas formas institucionais. Gonzalo (2002) também segue a mesma linha de análise, buscando articular a questão da empregabilidade à formação/qualificação profissional. Já em uma linha de análise mais crítica, Fidalgo (1999) estabelece relações entre as experiências de negociação da formação profissional francesa e brasileira.

TrabalhoNecessário - www.uff.br/trabalhonecessario; Ano 11, № 16/2013. 


\section{Trabalhonecessário}

Issn: 1808 - 799X

ano 11, no $16-2013$

representando seus próprios interesses, seriam capazes de abordar em conjunto as demandas de capacitação, sejam daqueles setores e ocupações novas e emergentes, em especial, ou daqueles que ainda estão em processo de reconversão. O elemento catalisador dos interesses dos diferentes sujeitos sociais seria, portanto, o único propósito de encontrar vias de solução para a erradicação dos conflitos que eles próprios conservam em sua natureza, efetivando desse modo a conciliação de seus interesses mediante o acordo mútuo.

Mas é inegável que, mesmo com seu caráter pragmático e livre de qualquer capacidade de crítica ao capital, esse tipo de bibliografia tem cumprido um papel significativo, na medida em que tem conseguido ilustrar a reformulação da estrutura institucional da oferta e da demanda de formação/qualificação profissional. Essa bibliografia também tem prestado valioso serviço, na medida em que tem se empenhado em divulgar a ampliação dos conceitos referentes à formação/qualificação profissional, concebendo-a não só como uma atividade de exclusiva responsabilidade do Estado, mas como um produto da negociação entre o Estado e o empresariado, o que inclui a participação de todos os sujeitos sociais, em especial os sindicatos e demais organizações da sociedade civil, operando de forma descentralizada, em nível local.

Outro elemento recorrente na bibliografia sobre a negociação coletiva da formação profissional é a crença de que as políticas públicas nesse campo exercem um papel relevante no enfrentamento da exclusão social, ao passo que o entendimento entre os sujeitos coletivos contribui para a eficácia da identificação da demanda, o que favorece a elaboração e realização de programas de capacitação dirigidos aos segmentos mais vulneráveis da força de trabalho - os trabalhadores precarizados. Entretanto, não é isso que verificamos nos países desenvolvidos, onde esse tipo de entendimento é uma prática social mais consolidada e com mais tempo de experiência que em países como Brasil. Um

TrabalhoNecessário - www.uff.br/trabalhonecessario; Ano 11, № 16/2013. 


\section{Trabalhonecessário}

Issn: 1808 - 799X

ano 11, no $16-2013$

dos problemas enfrentados na gestão de políticas de formação/qualificação na França, por exemplo, é a constatação de que os segmentos da força de trabalho portadores de contrato de trabalho, com maior qualificação e com melhores condições de trabalho são os mais beneficiados pelos programas de qualificação, em detrimento de segmentos mais necessitados (Cf.: Fidalgo, 1999).

Ao abordar a trajetória dos acordos nacionais de formação profissional continuada na Espanha, Sanz (1997) indica que esses acordos prevêem o desenvolvimento de um processo que visa pôr à disposição das empresas e dos trabalhadores um sistema de formação profissional sustentado no diálogo social e na responsabilidade direta dos próprios protagonistas da atividade econômica. Embora esse caráter dos acordos esteja muito mais próximo da minimização do papel do Estado do que da efetivação da democracia preconizada pelo tripartismo e/ou paritarismo, Sanz expressa muito entusiasmo a esse respeito. Para essa autora, a interlocução de empresários e de trabalhadores no sistema de formação continuada produz uma cultura de negociação e uma soma de esforços em relação às exigências planejadas para a formação continuada que acabará também por produzir efeitos positivos em outros âmbitos da relação de trabalho. Acredita a autora que a participação conjunta de empresários e trabalhadores ao longo de todo o processo de gestão do sistema contribui para tornar possíveis os esforços complementares que a formação continuada requer, tanto do ponto de vista da empresa, em termos de investimentos e de compromisso para suas capacidades gerenciais, como do ponto de vista dos trabalhadores, em termos de motivação, de dedicação e de disponibilidade para participar de atividades formativas que nem sempre podem coincidir com os horários de trabalho.

É óbvio que Sanz (1997) tem conhecimento de que os objetivos fundamentais desses acordos e das políticas deles originadas visam à promoção do desenvolvimento pessoal e profissional dos trabalhadores, à melhoria da competitividade das empresas, à adaptação da força de trabalho às inovações

TrabalhoNecessário - www.uff.br/trabalhonecessario; Ano 11, № 16/2013. 


\section{Trabalhonecessário}

Issn: 1808 - 799X

ano 11, no $16-2013$

tecnológicas e à promoção do desenvolvimento de novas atividades econômicas. Mesmo assim a autora não formula nenhuma crítica, conformando-se com a ótica empresarial. O fato de esses acordos buscarem a adequação do sistema de formação continuada espanhol às demandas do setor produtivo sequer é questionado pela autora.

Seguindo essa lógica de relação mercantil, especialmente a partir do Governo FHC, o Estado brasileiro vem utilizando mecanismos renovados de obtenção do consentimento ativo dos trabalhadores e demais setores organizados da sociedade civil, abdicando da utilização freqüente de seu poder coercitivo, passando a buscar cada vez mais o consentimento ativo dos trabalhadores - 0 que não significa, necessariamente, uma forma democrática de ação governamental. Tentaremos então fazer uma breve exposição das diretrizes gerais que nortearam a ação estatal no campo da educação profissional.

Nessa linha de ação, sua primeira investida no sentido de reformular o sistema de formação profissional se deu por meio de um Projeto de Lei (PL 1603/95) que, como observa Moraes (1998, p. 107), desrespeitava o processo de discussão e elaboração de propostas desencadeado na época pelos docentes das Instituições Federais de Ensino Técnico-Profissional (IFET's). Esse Projeto de Lei provocara críticas severas e recebera mais de 300 emendas. Mas com a aprovação da LDB (Lei 9394/96), o governo optou por retirar seu Projeto, inviabilizando o debate pelas vias institucionais sobre o tema. Sua opção foi baixar por decreto as reformas que pretendia implementar nessa modalidade de ensino. "Essa nova legislação para a reforma do ensino profissionalizante (Decreto 2208/97 e Portaria 646/97) prejudica todo o empenho e as lutas democráticas por uma educação integrada" (Militão, 1998, p. 100).

Desde o processo de discussão da LDB desencadeado logo após a promulgação da constituinte, havia em alguns movimentos sociais de caráter popular e democrático uma crítica à dualidade entre formação para o trabalho e

TrabalhoNecessário - www.uff.br/trabalhonecessario; Ano 11, № 16/2013. 


\section{Trabalhonecessário}

Issn: 1808 - 799X

ano 11, no $16-2013$

formação básica típica da escola capitalista. Em seu lugar, buscava-se um modelo alternativo de escola que viesse a unificar trabalho e educação na prática educativa. De modo geral, a concepção marxista de unificação escolar sempre serviu de referência a estas proposições ${ }^{8}$. Em linhas gerais, as proposições anticapitalistas pautavam-se na idéia de omnilateralidade e viam no trabalho 0 princípio educativo capaz dar materialidade a este tipo de formação ${ }^{9}$.

Observe-se que as diretrizes básicas da educação profissional haviam sido estabelecidas pelo $\S 2^{\circ}$ do Artigo 36 e pelos Artigos 39 a 42, da LDB. O Decreto № 2.208, de 17 de abril de 1997, na realidade, regulamenta essas diretrizes. No artigo $1^{\circ}$ deste Decreto estão previstos os seguintes objetivos para a educação profissional:

I.promover a transição entre a escola e o mundo do trabalho, capacitando jovens e adultos com conhecimentos e habilidades gerais e específicas para o exercício de atividades produtivas;

II.proporcionar a formação de profissionais, aptos a exercerem atividades específicas no trabalho, com escolaridade correspondente aos níveis médio, superior e de pósgraduação;

III.especializar, aperfeiçoar e atualizar o trabalho em seus conhecimentos tecnológicos;

IV.qualificar, reprofissionalizar e atualizar jovens e adultos trabalhadores, com qualquer nível de escolaridade, visando a sua inserção e melhor desempenho no exercício do trabalho.

Os problemas da política de formação/qualificação profissional começam já a partir de seus objetivos, especialmente no que concerne à relação entre escola e mundo do trabalho. Em lugar de constituir uma unidade interativa entre escola e

\footnotetext{
${ }^{8}$ Esta tendência crítica à dualidade da escola capitalista se fez expressar no Substitutivo Jorge Hage do Projeto de Lei de Diretrizes e Bases da Educação Nacional aprovado na Câmara de Deputados e enviado ao Senado. Entretanto, este projeto foi completamente alterado pelo relator, Senador Darcy Ribeiro, de modo a descaracterizar todos os avanços conquistados pelo movimento social no que concerne à relação entre educação básica e formação profissional.

9 Diversos autores brasileiros preocuparam-se com a sistematização desta concepção pedagógica. Dentre eles, poderíamos citar o trabalho de Machado (1991), onde faz uma rica distinção entre a proposta burguesa e a proposta socialista de unificação escolar. Além deste, poderíamos citar também o trabalho de Nogueira (1993) que aborda a relação trabalho e educação na obra de Marx e Engels. Outro trabalho de grande envergadura é o de Manacorda (1991), que sistematiza os fundamentos da pedagogia marxista.
} 


\section{Trabalhonecessário}

Issn: 1808 - 799X

ano 11, no $16-2013$

trabalho, a proposição contida no Decreto 2208/97 restringe-se a uma mera divisão do trabalho educacional, onde à educação profissional cabe o papel de fornecer a qualificação social necessária - na forma de conhecimentos e habilidades gerais para o exercício de atividades produtivas - para jovens e adultos se adaptarem às novas demandas de produtividade e competitividade. Além desta função, também à educação profissional cabe a formação técnicooperacional - na forma de aquisição de conhecimentos e habilidades específicas para o exercício de atividades produtivas. À empresa, cabe a tarefa de treinar o trabalhador já formado/qualificado pela Rede de Educação Profissional, de acordo com as necessidades produtivas de uma função específica. A relação entre empresa e escola prevista no Decreto 2208/97 não ultrapassa aquela existente entre o cliente (empresa) e o fornecedor de serviços (escola). Nesta relação, a escola de educação profissional cumpre uma dupla função. Além de formar quadros minimamente qualificados para ocupar os escassos postos de trabalho, também servem de instrumento de conformação de classe para contingentes cada vez maiores de trabalhadores desempregados, na medida em que transfere para o trabalhador certificado por ela a responsabilidade de seu sucesso ou fracasso no mercado de trabalho.

Prevista para ser desenvolvida de forma articulada ao ensino regular ou em modalidades que contemplem estratégias de educação continuada, a educação profissional passou a contar com as escolas do ensino regular, as instituições especializadas ou o ambiente de trabalho como espaços para sua realização. Também passou a compreender três níveis de ensino: a educação profissional de nível básico (formação inicial e continuada), técnico e tecnológico.

Segundo o que está disposto nos incisos do Art. 3ํ do Decreto 2208/97, a educação profissional de nível básico, destina-se "à qualificação e reprofissionalização de trabalhadores, independente de escolaridade prévia". Trata-se de uma modalidade de educação não formal, de duração variável, 


\section{Trabalhonecessário}

Issn: 1808 - 799X

ano 11, no $16-2013$

"destinada a proporcionar ao cidadão trabalhador conhecimentos que the permitam reprofissionalizar-se, qualificar-se e atualizar-se para o exercício de funções demandadas pelo mundo do trabalho, compatíveis com a complexidade tecnológica do trabalho, o seu grau de conhecimento técnico e o nível de escolaridade do aluno, não estando sujeita à regulamentação curricular" (Art. $4^{\circ}$ ). Este nível de ensino deve ser oferecido, obrigatoriamente, pelas instituições públicas e privadas sem fins lucrativos que ministram educação profissional e recebem apoio financeiro do Poder Público ${ }^{10}$. Estes cursos devem ser abertos a alunos das redes públicas e privadas de educação básica, assim como a trabalhadores de qualquer nível de escolaridade, devendo a estes ser conferido certificado de qualificação profissional.

A educação profissional de nível técnico destina-se a proporcionar habilitação profissional a alunos matriculados ou egressos do ensino médio, devendo ser ministrada na forma estabelecida pelo Decreto 2208/97, obedecendo à organização curricular própria e independente do ensino médio. Este nível da educação profissional poderá ser oferecido de forma concomitante ou seqüencial ao ensino médio. As disciplinas de caráter profissionalizante, eventualmente cursadas na parte diversificada do ensino médio, poderão ser aproveitadas no currículo de habilitação profissional, independente de exames específicos, desde que não ultrapassem o limite de $25 \%$ do total da carga horária mínima deste nível de ensino.

Embora esteja previsto que a formulação de diretrizes curriculares nacionais (carga horária mínima, conteúdos mínimos, habilidades e competências básicas, por área profissional) dos currículos plenos dos cursos do ensino técnico seja estabelecida pelo Mec, ouvido o Conselho Nacional de Educação (CNE), até o momento estes parâmetros curriculares nacionais da educação profissional ainda

\footnotetext{
${ }^{10}$ Observe-se que, apesar desta prerrogativa, o "Sistema S" normalmente cobra taxas pelos serviços prestados, apesar de seus cursos serem, na maioria das vezes, mantidos com recursos do FAT.
}

TrabalhoNecessário - www.uff.br/trabalhonecessario; Ano 11, № 16/2013. 


\section{Trabalhonecessário}

Issn: 1808 - 799X

ano 11, no $16-2013$

não foram estabelecidos. $\mathrm{O}$ que se tem de concreto é o que está previsto no Decreto 2208/1997, que estabelece em seu Art. 6º, inciso III, que o currículo básico não poderá ultrapassar setenta por cento da carga horária mínima obrigatória, ficando reservado um percentual mínimo de trinta por cento para que os estabelecimentos de ensino, segundo seus interesses, elejam disciplinas, conteúdos, habilidades e competências específicas para sua organização curricular. Também estão previstos currículos experimentais não contemplados em diretrizes nacionais, desde que previamente aprovados pelo sistema de ensino competente.

A educação profissional de nível tecnológico corresponde a cursos de nível superior na área tecnológica, destinados a egressos do ensino médio e técnico. Estes cursos conferirão diplomas de tecnólogos e devem ser estruturados para atender aos diversos setores da economia, abrangendo áreas especializadas.

O mecanismo político de que o governo lançou mão para garantir a legitimação da reforma da educação profissional foi a elaboração de um diagnóstico acerca das IFET's, "apontando-as como elitistas, de ensino caro, com um grau de abrangência reduzido (100.000 alunos/ano), mas com um ensino médio de boa qualidade, superior ao ensino propedêutico regular privado" (Militão, 1998, p. 101). Com base em um discurso defensor da flexibilização e da "democratização" do ensino técnico-profissionalizante, o Governo propôs a expansão da rede com a manutenção da qualidade, garantida por instrumentos de avaliação permanente. Mas, na compreensão de Militão (Ibidem), "essas palavras perdem o seu significado real, passando, na prática, a ter um significado contrário ao que se propõem".

Tal afirmação se pauta na observação de que a estrutura modular, como está disposto no Decreto 2208/97, "banaliza a formação profissional pela separação entre o saber e o fazer. $O$ conhecimento é separado em seus aspectos 


\section{Trabalhonecessário}

Issn: 1808 - 799X

ano 11, no $16-2013$

teóricos e práticos, resultando em um conhecimento meramente instrucional de menor qualidade" (Militão, 1998, p. 101).

Como se pode notar, o Governo FHC tomou como base os dispositivos legais previstos na nova LDB para instrumentalizar, por meio de decretos e portarias ministeriais, sua política de educação profissional. Se por um lado acionou seu poder de coerção para sufocar as vozes contrárias à sua política, oriundas das entidades de representação dos trabalhadores das IFET's, por outro lado, o Governo FHC buscou o consentimento ativo dos trabalhadores por meio do discurso da democratização do acesso ao ensino profissionalizante de boa qualidade, o que soa bem aos ouvidos do imenso contingente de trabalhadores desempregados e carentes de qualificação profissional. Conforme descreve 0 próprio documento do BID (BID apud Militão, 1998, p. 101-102), em seus aspectos mais gerais, essa reforma introduz a separação administrativa e curricular dos conteúdos profissionalizantes dos de ensino geral médio, liberando a educação básica (ensino fundamental e médio) para concentrar seus esforços na formação para o trabalho no sentido lato, ou seja, na formação de habilidades cognitivas e competências nas áreas de conhecimento acadêmico. Por outro lado, essa reforma permite a institucionalização de uma educação profissional vinculada aos interesses imediatos do mercado de trabalho que, na avaliação de seus formuladores, tem o potencial de estimular o desenvolvimento de uma educação profissional de nível pós-médio.

Tal reforma atualiza o debate em que se confrontam historicamente as diferentes concepções de formação para o trabalho na sociedade de classes. Trata-se da disputa de hegemonia que se expressa no confronto das idéias acerca da relação entre educação básica e educação profissional suscitado pelo conjunto de reformas empreendidas pelo Estado brasileiro no campo da educação profissional. Se considerarmos que, no Brasil, à educação básica se atribui o papel de formação geral e à educação profissional, o papel de formação para o

TrabalhoNecessário - www.uff.br/trabalhonecessario; Ano 11, № 16/2013. 


\section{Trabalhonecessário}

Issn: 1808 - 799X

ano 11, no 16 - 2013

trabalho, devemos supor que, ao tratarmos da relação entre ambas as modalidades educacionais, necessariamente, estaremos refletindo sobre um tipo específico de relação entre trabalho e educação no processo de aquisição do conhecimento e suas contradições.

Quem deflagrou a reforma da educação profissional no Brasil foi o Governo FHC. O Plano de Governo de Fernando Henrique Cardoso (Cardoso, 1994; 1998) apresentava como desafio a redefinição de um modelo de desenvolvimento que, segundo sua concepção de mundo, pudesse abrir para o Brasil a perspectiva de um futuro melhor para o conjunto da sociedade. Para isso colocava três condições básicas: 1) refazer o esquema de financiamento do desenvolvimento; 2) eleger a criação de empregos como forma mais efetiva e duradoura de distribuição de renda; e 3) reorganizar o Estado, fortalecendo o poder público decisório para a realização eficiente de projetos sociais compensatórios e para a defesa dos interesses nacionais em plano internacional.

O Programa do Governo FHC propunha um modelo de desenvolvimento economicamente sustentado, de participação ativa na vida internacional, de abertura para o mundo; modelo de "justiça social" onde o direito à vida com dignidade fosse garantido, assegurando a inserção inteligente da economia brasileira no mercado globalizado. Como estratégias para o desenvolvimento, 0 Partido Social Democrata Brasileiro (PSDB) previa a estabilidade econômica e a política de intercâmbio internacional.

Esse programa apresentava como estratégia para evitar monopólios e abusos do Estado, decorrentes da situação de concentração de poder econômico, uma crescente parceria com o setor privado na propriedade e gestão da infraestrutura nacional, exigindo, assim, a redefinição do papel do Estado como indispensável à estabilidade econômica, ao desenvolvimento sustentado e à correção das desigualdades. Presumia-se que a parceria entre Governo e sociedade deveria criar novos canais de participação e controle público e

TrabalhoNecessário - www.uff.br/trabalhonecessario; Ano 11, № 16/2013. 


\section{Trabalhonecessário}

Issn: 1808 - 799X

ano 11, no $16-2013$

dinamizar os já existentes - desprivatização do Estado -; deveria promover a multiplicação de espaços de negociação de conflitos, definir e apoiar novas formas de parceria nos diversos níveis de governo, apoiar e desenvolver formas amplas e criativas de parceria entre Governo e sociedade (ONGs, empresas, sindicatos e universidade).

Partindo do princípio de que, na economia globalizada, a competição é determinada principalmente pelas conquistas científicas e tecnológicas (Cardoso, 1994, p. 15), este programa apresentava uma política tecnológica voltada para o apoio à indústria nacional, na promoção do aumento da sua capacidade de inovar em seus processos produtivos e gerenciais e de incorporar os conhecimentos científicos e tecnológicos disponíveis internacionalmente, onde governo e iniciativa privada, articulados na geração de uma estrutura eficiente em ciência e tecnologia, promovessem, em curto prazo, a reorganização e modernização tecnológica do setor. Como estratégia, propõe a ampliação dos investimentos do Estado em ciência e tecnologia, utilizando recursos orçamentários, privatização, financiamento internacional e novas parcerias com setor privado.

No campo educacional, o programa de governo de FHC considerava que o País tinha muito a avançar na reforma da educação e nos estímulos ao desenvolvimento de ciência e tecnologia, para que viesse a ter condições de forjar um novo modelo de desenvolvimento, impulsionasse inadiáveis transformações sociais e alcançasse presença significativa na economia mundial. A educação assumia, assim, um caráter de instrumento de competitividade e produtividade industrial.

A prioridade fundamental da política educacional do Plano de Governo FHC consistia em incentivar a universalização do acesso ao primeiro grau (atual ensino fundamental) e melhorar a qualidade do atendimento escolar (oito séries de ensino obrigatório). Entretanto, não fazia relação clara entre a política para a formação básica e a de desenvolvimento científico e tecnológico. Tal lacuna 


\section{Trabalhonecessário}

Issn: 1808 - 799X

ano 11, no $16-2013$

refletia o fato de a política educacional ser orientada pelo princípio da "empregabilidade", em lugar do princípio da qualidade de vida.

Em função disso, o ensino médio era visto como nível estratégico do sistema educacional, pois possibilitava a preparação para o trabalho, aumentando a qualificação dos jovens e as suas oportunidades de obter emprego. A atualização profissional, uma das prioridades de seu plano de governo, estaria em consonância com as exigências de qualificação impostas pela vida moderna e pelas novas demandas do MTb, em parceria com empresas privadas, sindicatos, Senai e Senac.

Em suma, o plano de governo de $\mathrm{FCH}$ atribuía à educação o papel de formação e qualificação da força de trabalho, com base em um patamar mais avançado de uso diretamente produtivo da ciência e da tecnologia no trabalho e na vida urbano-industrial, com vistas na garantia de maior produtividade $\mathrm{e}$ competitividade das empresas como diferencial de competitividade no mercado globalizado. Para isso, buscou explicitar os vínculos da educação com o mundo do trabalho, dentro dos limites da valorização do capital.

Seguindo essa linha de argumentação, logo no primeiro ano de mandato, o Governo FHC estabeleceu como prioridade a consolidação da frágil estabilidade econômica do país, obtida via Plano Real, e a construção do desenvolvimento sustentado com eqüidade social. Leia-se, entretanto, nas entrelinhas deste discurso, a deflagração de esforços governamentais no sentido de mobilizar a aparelhagem estatal para a garantia de condições de inserção subalterna do país no mercado globalizado. Nesse processo, coube ao MTb duas grandes vertentes de atuação: a) a missão de modernizar as relações de trabalho no país, em busca da superação dos resquícios do populismo e do período autoritário da Era Vargas; b) a consolidação de uma política pública de trabalho e de educação profissional (Brasil, 1995, p. 12). 


\section{Trabalhonecessário}

Issn: 1808 - 799X

ano 11, no $16-2013$

Assim, sob o comando de Nassim Mehedff, coube à Secretaria de Formação e Desenvolvimento Profissional (Sefor), do MTb, a tarefa de recolocar a questão da educação profissional na ordem do dia, propondo uma estratégia de atuação pautada em três dimensões: na reformulação conceitual, na articulação institucional e na construção de um novo tipo de relação entre Estado e sociedade civil.

As linhas de ação estabelecidas no plano estratégico da Sefor extrapolam o plano de ação imediato deste órgão, aferindo-lhe tarefas muito mais amplas do que a atividade operacional. Além da operacionalização da educação profissional do país, coube à Sefor, também, a consolidação institucional do MTb como órgão responsável pela articulação da política de trabalho e de educação profissional do país, bem como a promoção de uma nova metodologia de gestão de políticas sociais no bojo da estratégia do governo. Portanto, além de gerir a Rede de Educação Profissional (Rep), a Sefor assume também a tarefa de conformação política e ideológica, funcionando como mecanismo de mediação do conflito de classe e de construção do consenso em torno da política pública de formação profissional implementada pelo Governo Federal, ou seja: assume o papel de aparelho de manutenção da hegemonia por excelência.

A política de educação profissional implementada no país, a partir de 1995 , sob a orientação política e operacional da Sefor, fundamenta-se em cinco eixos fundamentais (Brasil, 1995, p. 07-10):

- Aprender a aprender: a eminência de um novo perfil de qualificação que demanda do trabalhador não mais a habilidade de saber fazer, mas de conhecer e, acima de tudo, saber aprender.

- Empresa competitiva, cidadão competente: o resgate da qualificação extrapola a dimensão técnica, envolve também uma dimensão de cidadania, ou seja, as competências exigidas pelo atual padrão de desenvolvimento científico e tecnológico dos processos produtivos tendem a tornarem-se requisito para a vida em sociedade.

- O repensar da educação: negação da visão dicotômica entre educação básica e profissional dentro dos limites da valorização do capital, de modo que a educação profissional assuma um caráter complementar e integrado à educação básica.

TrabalhoNecessário - www.uff.br/trabalhonecessario; Ano 11, № 16/2013. 


\section{Trabalhonecessário}

Issn: 1808 - 799X

ano 11, no $16-2013$

- Foco no mercado: é preciso restabelecer o foco da educação profissional na empregabilidade, evitando-se a visão contencionista ou assistencialista.

- Articulação entre emprego, trabalho e educação profissional: inserir as políticas de educação/formação no conjunto das políticas públicas de trabalho e renda, situando-as no contexto de um novo padrão de relações capital-trabalho, fundado na negociação.

Com base nesses eixos fundamentais, as ações da SEFOR ficaram assim definidas pelo Governo FHC (BRASIL, 1995, p. 16):

a) consolidar e difundir um novo conceito de educação profissional, como elemento indissociável do desenvolvimento sustentável, que não se confunde com assistencialismo nem substitui educação básica;

b) restabelecer o papel da Educação profissional, como processo com começo, meio e fim, com foco no mercado de trabalho, tendo em vista a empregabilidade da clientela;

c) promover o desenvolvimento didático-metodológico - envolvendo currículos, programas e recursos instrucionais (livros, vídeos, softwares) - adequados a processos de qualificação e requalificação profissional que levem em conta as peculiaridades e condições das diferentes clientelas - trabalhadores inseridos em processos de modernização, desempregados, jovens de baixa escolaridade, excluídos - das diversas regiões do país;

d) fomentar o desenvolvimento de metodologias e sistemas que dêem suporte ao atendimento integrado ao trabalhador, em matéria de orientação e análise ocupacional, informação sobre o mercado de trabalho;

e) consolidar e difundir essa base conceitual-metodológica no âmbito tanto do Ministério do Trabalho, como das agências de educação profissional e dos órgãos e entidades envolvidos no projeto.

Para operacionalizar essas ações, a SEFOR construiu gradativamente o Pano Nacional de Qualificação do Trabalhador (PLANFOR). Este arranjo institucional visa integrar diferentes projetos de qualificação e requalificação profissional desenvolvidos por diferentes sujeitos em todo o país. Trata-se de um dos mecanismos da Política Pública de Trabalho e Renda (PPTR), iniciados em 1995, no âmbito do Fat, destinado à conformação das atividades de qualificação profissional, segundo as orientações e diretrizes estabelecidas pelo Governo Federal. Por se tratar de um programa prioritário do Governo Federal, o Planfor integra o Plano Plurianual de Investimentos (PPA) 2000/2003 e tem como objetivo:

TrabalhoNecessário - www.uff.br/trabalhonecessario; Ano 11, № 16/2013. 


\title{
Trabalhonecessário
}

Issn: 1808 - 799X

ano 11, no $16-2013$

\begin{abstract}
Garantir uma oferta de educação profissional permanente, no âmbito da PPTR, que contribua para: reduzir o desemprego e o subemprego da População Economicamente Ativa (PEA); combater a pobreza e a desigualdade social; elevar a produtividade, a qualidade e a competitividade do setor produtivo. Em outras palavras, o PLANFOR trata de promover a qualificação profissional como direito do trabalhador e componente básico do desenvolvimento sustentado, com eqüidade social (BRASIL, 2001, p. 07).
\end{abstract}

O Planfor tem como meta global a garantia de oferta de educação profissional, a médio e longo prazo, suficiente para qualificar anualmente, pelo menos, $20 \%$ da População Economicamente Ativa (Pea) ${ }^{11}$. Segundo o governo, "esse percentual é o mínimo necessário para garantir, de cinco em cinco anos, uma chance de atualização profissional para cada trabalhador, o que ainda é pouco no mundo de hoje, com mudanças tão rápidas" (Brasil, 2001, p. 7-8). Para atingir tal meta, o Planfor se propõe a:

[...] articular e consolidar parcerias, mobilizando a capacidade e a competência da Rede de Educação Profissional do País (REP), de modo a ampliar e otimizar os recursos do FAT. A premissa é que o FAT possa financiar a qualificação de cerca de $7 \%$ da PEA ao ano, ficando os $13 \%$ restantes por conta de outros fundos públicos e privados [...] (p. 8). Explica que os recursos do FAT aplicados no PLANFOR têm dois focos: "atender a grupos vulneráveis, que têm dificuldade de acesso a alternativas de qualificação profissional; 'alavancar' ou 'catalisar' recursos de parcerias, com o setor público ou privado, para ampliar o raio de cobertura do PLANFOR" (BRASIL, 2001, p. 8).

O público alvo do Planfor está definido a partir de dois grupos. O primeiro é chamado de grupo de vulneráveis ${ }^{12}$, para o qual são garantidos $80 \%$ dos recursos e $90 \%$ das vagas. Este grupo se subdivide em quatro categorias: a) pessoas desocupadas; b) pessoas em risco de desocupação permanente ou conjuntural;

${ }^{11}$ Considerando-se que a idade mínima admitida para o trabalho é de 16 anos e que a PEA, segundo dados de 2001, é de cerca de 75 milhões de pessoas, ocupadas ou desocupadas, a meta global do PLANFOR, então, é qualificar 15 milhões de pessoas anualmente.

12 Para o Governo, vulnerabilidade significa a "[...] dificuldade de acesso ao trabalho e a alternativas de qualificação profissional, por razões de pobreza, baixa escolaridade e outros fatores de discriminação e seletividade no mercado de trabalho" (BRASIL, 2001, p. 13).

TrabalhoNecessário - www.uff.br/trabalhonecessario; Ano 11, № 16/2013. 


\section{Trabalhonecessário}

Issn: 1808 - 799X

ano 11, no $16-2013$

c) empreendedores(as) urbanos/rurais; d) pessoas autônomas, cooperadas, autogeridas. O segundo grupo, para o qual o PLANFOR reserva até $10 \%$ das vagas e $16 \%$ dos recursos, é definido com base em prioridades locais/regionais. A qualificação de membros dos Conselhos Estaduais do Trabalho (CET'S) e Comissões Municipais do Trabalho (CMT's) e de outros conselhos/fóruns estaduais/ municipais deve ser incluída neste segundo grupo.

O novo enfoque metodológico e operacional da Educação profissional inaugurado pelo PLANFOR visa contemplar as seguintes dimensões:

- foco na demanda do mercado de trabalho e no perfil da população-alvo, orientada pela efetiva demanda do setor produtivo, reunindo interesses e necessidades de trabalhadores, empresários, comunidades;

- $\quad$ direito do cidadão produtivo, em bases contínuas, permanentes, em caráter complementar (e nunca substitutivo) à educação básica (fundamental e média), que é direito constitucional do cidadão;

- desenvolvimento integrado de habilidades básicas, específicas e/ou gestão do trabalhador, por meio de cursos, treinamentos, assessorias, extensão e outras ações, presenciais ou a distância;

- $\quad$ atenção à diversidade social, econômica e regional da Pea, promovendo a igualdade de oportunidades nos programas de qualificação e no acesso ao mercado de trabalho.

O Planfor está estruturado a partir de uma articulação institucional bastante complexa, definida como a construção e consolidação de uma nova institucionalidade da educação profissional no país. A partir desta nova institucionalidade, busca-se promover, ao mesmo tempo, a inserção e a contribuição do Planfor no quadro das políticas públicas do país. Isto implica em mobilização e fortalecimento de novos atores sociais, consolidando e integrando 


\section{Trabalhonecessário}

Issn: 1808 - 799X

ano 11, no $16-2013$

uma Rep para atuar na qualificação permanente da Pea, em bases participativas e descentralizadas (Brasil, 2001, p. 11). Desse modo o Planfor busca consolidarse como uma espécie de apoio à sociedade civil, na medida em que se propõe a promover, em ampla escala, ações de qualificação do trabalhador dirigidas à Pea, especialmente a grupos vulneráveis, incluindo não só cursos e treinamentos, mas assessorias, extensão, pesquisas e estudos (Brasil, 2001, p. 13).

A execução dos cursos/programas do Planfor se dá por intermédio de uma rede de educação profissional, formada por de cerca de 14 mil agências em todo o país ${ }^{13}$. Trata-se de organismos públicos e privados, federais, estaduais ou municipais, governamentais ou não, com ou sem fins lucrativos, abrangendo: a) universidades, faculdades, centros tecnológicos e institutos de ensino superior; b) escolas técnicas de nível médio; c) Sistema S (Senai, Sesi, Senac, Sesc, Senar, Sest, Senat, Sebrae); d) fundações, associações, sindicatos e centrais sindicais de trabalhadores; e) fundações, associações, confederações e federações de empresários; f) outras organizações de educação profissional (livres, comunitárias etc.) (Brasil, 2001, p. 13). Essas entidades executoras são selecionadas por meio de um processo aberto, podendo candidatar-se qualquer tipo de agência de educação profissional que atenda aos requisitos legais e técnicos definidos em le $\left.\right|^{14}$ e aos objetivos e diretrizes do Planfor (Brasil, 2001, p. 14).

O financiamento do Planfor se dá por meio do Fat, com recursos da rubrica "qualificação profissional", que são repassados aos estados da federação, ao Distrito Federal ou a Parceiros Nacionais/Regionais por meio de convênios firmados com o Codefat e o MTb. Cerca de $20 \%$ do valor financiado constitui contrapartida mínima dos estados e Distrito Federal fixada em lei. Os recursos

\footnotetext{
${ }^{13}$ Este número de agências componentes da REP foi estimado a partir de um cadastro feito pelo Governo entre 1996 e 1999. Como este cadastre vem sendo atualizado constantemente e o Governo tem incentivado as atividades de educação profissional em todo o país, acreditamos que este número tenha aumentado significativamente a partir de 2000.

${ }^{14}$ Os processos de contratação no setor público estão regulamentados na Lei № $8.666 / 93$, com as modificações da Lei № 8.883/94.
}

TrabalhoNecessário - www.uff.br/trabalhonecessario; Ano 11, № 16/2013. 


\section{Trabalhonecessário}

Issn: 1808 - 799X

ano 11, no $16-2013$

são distribuídos entre os Planos Estaduais de Qualificação (Peq's) segundo quatro critérios definidos na Resolução no 258/00 do Codefat: focalização, eficiência, continuidade e contrapartida.

A focalização é indicada pela distribuição da Pea total (maior de 16 anos), ponderada pela Pea de baixa escolaridade (até 03 anos de estudos) e em situação de pobreza. A eficiência é indicada pelo percentual de treinandos encaminhados ao mercado de trabalho após a conclusão do curso. A continuidade é indicada pela compensação mínima por parte dos estados, Distrito Federal ou Parceiros Nacionais/Regionais para garantir os níveis de execução já atingidos, evitando o decréscimo da oferta de oportunidades de educação profissional. A contrapartida é indicada pela quantidade de investimento de recursos adicionais, além da contrapartida mínima fixada em lei, por parte dos estados, Distrito Federal ou Parceiros Nacionais/Regionais (Brasil, 2001, p. 14).

O gerenciamento do Planfor se dá de forma descentralizada, por meio de uma cadeia estratégica e operacional estruturada em três níveis: federal, estadual e municipal. No nível federal, as instâncias gestoras são: o Codefat, o MTE, a Secretaria de Políticas Públicas de Emprego (SPPE) e o Departamento de Qualificação Profissional (DEQP). No nível estadual, as instâncias gestoras são: os Conselhos Estaduais de Trabalho e Secretarias de Trabalho ou equivalentes. No nível municipal, as instâncias gestoras são: os Conselhos Municipais de Trabalho ou equivalentes (Brasil, 2001, p. 15).

O Planfor conta, ainda, com um sistema de monitoramento e avaliação que inclui quatro mecanismos integrados e complementares: a) acompanhamento técnico-gerencial de cada Peq/Parc; b) avaliação externa e acompanhamento de egressos do Peq/Parc; c) supervisão técnico-operacional do Planfor (a cargo do MTE/SPPE/DEQP); d) avaliação nacional do Planfor (a cargo do MTE/SPPE/DEQP e/ou do Codefat). 


\section{Trabalhonecessário}

Issn: 1808 - 799X

ano 11, no $16-2013$

Tomando como referência empírica a implantação do Planfor, Cêa busca evidenciar duas questões que para nós são bastante oportunas: "uma referente à relação entre as políticas de qualificação profissional e a reforma do Estado Brasileiro e uma segunda relativa à cisão entre educação escolar e formação do trabalhador que se materializa a partir de tais políticas" (Cêa, 2000, p. 95).

O Planfor é definido por Cêa como um instrumento de execução das políticas públicas de emprego que expressa o campo principal da educação profissional, materializando-a como modalidade educacional. $\mathrm{Na}$ avaliação da autora, o Planfor opera a ruptura entre qualificação para o trabalho e elevação dos níveis de escolaridade. Além disto, constitui uma experiência que vem se desenvolvendo por uma dinâmica tripartite. O Planfor, na realidade, reflete...

\footnotetext{
Uma tendência mundial de crescimento da importância da formação profissional como parte das políticas relacionadas ao emprego, de modo que tais políticas acabam por caracterizarem-se como ações específicas, pontuais e direcionadas para o mercado de trabalho, as quais se delegam importante papel na reconstituição das relações sociais via estabilização dos níveis de emprego e/ou criação de formas de geração de renda (CÊA, 2000, p. 94).
}

Justamente por esta razão, a autora procura estabelecer relação entre as políticas de qualificação profissional e a reforma do Estado Brasileiro e, no bojo dessa relação, trazer à tona a cisão entre a educação escolar e a formação profissional que se materializa a partir de tais políticas. Curiosamente, esta cisão se constitui sobre o discurso da superação da dicotomia entre educação básica e profissional. $\mathrm{Na}$ verdade, o que o governo propõe como superação dessa dicotomia nada mais é do que uma divisão do trabalho educativo de formação do novo trabalhador, onde à educação básica compete a formação de competências sociais - conformação ético-política do trabalhador - e à educação profissional compete a formação de competências técnico-operacionais - conformação psicofísica do trabalhador. De posse desse arsenal de competências, resta à 


\section{Trabalhonecessário}

Issn: 1808 - 799X

ano 11, no $16-2013$

empresa apenas o acionamento de suas estratégias gerenciais para consolidar a captura da subjetividade operária em favor da valorização do capital.

Tudo indica que a avaliação de Fogaça (Op. Cit.), quando indica que o Planfor está fadado à ineficácia, por repassar para os trabalhadores a responsabilidade da crise do emprego, na medida em que a certificação não se reverte em colocação no mercado de trabalho, está completamente equivocada. O que Fogaça não percebeu em suas análises é que esta ineficácia do Planfor reside exatamente na sua capacidade de camuflar sua ineficácia. Por isto, tendemos a concordar com a observação de Cêa (lbidem), quando afirma que, embora a avaliação externa nacional do Planfor realizada pela Unitrabalho aponte - Plano como uma política compensatória que penaliza os setores mais precarizados da força de trabalho, a sua continuidade é certa, assim como a manutenção de suas metas e a acentuação de seu ritmo.

A engenharia inaugurada pelo Planfor instaura um dos mecanismos mais eficientes de mediação do conflito de classe da burguesia. Em nenhum outro tem ocorrido tanta eficácia na conquista do consenso em torno da concepção burguesa de produção e reprodução social da vida material. Por meio do Planfor, a burguesia conseguiu conquistar o consentimento ativo dos trabalhadores em torno de suas políticas públicas de trabalho e renda. Assim, o projeto educativo do empresariado tem se tornado cada vez mais hegemônico, em detrimento do projeto de unificação entre educação e trabalho historicamente construído na luta dos trabalhadores contra o capital.

Já no governo de Luiz Inácio Lula da Silva, a partir da Resolução do Codefat № 333/2003 (Brasil, 2003), entretanto, abriram-se novas perspectivas para as Comissões Municipais de Trabalho e Renda (CMTR). Este documento institui o Plano Nacional de Qualificação (PNQ) e estabelece novos critérios para a transferência de recursos do Fat destinados à qualificação profissional e geração de emprego e renda. Esta Resolução inclui as secretarias municipais de trabalho

TrabalhoNecessário - www.uff.br/trabalhonecessario; Ano 11, № 16/2013. 


\section{Trabalhonecessário}

Issn: 1808 - 799X

ano 11, no $16-2013$

e/ou arranjos institucionais municipais no leque de instituições conveniadas para a execução de ações financiadas pelos recursos do Fat. Embora esses convênios sejam restritos a municípios com mais de 01 milhão de habitantes, existe a possibilidade de convênios com micro ou mesorregiões, abrindo espaços para que diversos municípios se articulem em torno de uma política unificada para combater os efeitos desemprego estrutural.

Entretanto, em função de inúmeras dificuldades para a concretização desses arranjos meso-regionais, por meio da Resolução no 466/2006, o Codefat deliberou pela flexibilização da legislação, reduzindo para 300 mil o número mínimo de habitantes para que um município possa pleitear ações de trabalho, qualificação e geração de renda de forma autônoma. Em busca de maior autonomia em relação aos Planos Estaduais de Qualificação, diversos municípios de médio e grande porte, mas com menos de um milhão de habitantes, passaram a ter possibilidade elaborar se próprio plano de qualificação e gerir autonomamente sua política pública de trabalho, qualificação e geração de renda.

Observamos que, em nome da busca de recomposição das bases de acumulação para o mercado local, com vistas na garantia de emprego e renda como alternativa à crise econômica que se instalou no país, trabalhadores, empresários e governos municipais se empenham para unir esforços em torno de interesses comuns. A política nacional de qualificação, por intermédio do Codefat, das Comissões Estaduais e/ou municipais Tripartites e Paritárias, se constitui ambiente privilegiado de concretização de práticas sociais de mediação do conflito de classe em busca da adesão das massas trabalhadoras ao projeto de política pública de trabalho e renda do Governo Federal. Visto como o único horizonte possível, o PNQ passa a gozar do consentimento ativo das massas de trabalhadores, na medida em que suas representações têm abdicado do seu papel de intelectuais responsáveis pela elaboração de projetos alternativos para disputar na sociedade a hegemonia nesse campo político. De acordo com esta

TrabalhoNecessário - www.uff.br/trabalhonecessario; Ano 11, № 16/2013. 


\section{Trabalhonecessário}

Issn: 1808 - 799X

ano 11, no $16-2013$

lógica perversa, a experiência do diálogo social para o controle do uso dos recursos do Fat ao mesmo tempo em que pode se materializar em um fórum de socialização dos mecanismos de controle social das decisões estatais, paradoxalmente, também pode se materializar num mecanismo de mediação do conflito de classe no âmbito municipal.

Concluímos que a gestão dos recursos do FAT aplicados em qualificação profissional, antes de desempenhar o papel de formação e de qualificação permanente da força de trabalho, desempenha o papel de conformação social de uma parcela significativa do conjunto dos trabalhadores desempregados e de trabalhadores precarizados. Em lugar de inserir este contingente de trabalhadores no mercado de trabalho, a gestão desses recursos acaba funcionando como um mecanismo de mediação do conflito de classe, diluindo a pressão política desses segmentos ao poder público e ao empresariado. 


\section{Trabalhonecessário}

Issn: 1808 - 799X

ano 11, no $16-2013$

\section{Referências}

ANTUNES, Ricardo. Os Sentidos do Trabalho: ensaio sobre a afirmação e a negação do trabalho. 3a Edição. São Paulo: Boitempo, 2000. 259 p.

BRASIL. Lei 9394, de 20 de dezembro de 1996. Estabelece as Diretrizes e Bases da Educação Nacional. Diário Oficial [da República Federativa do Brasil], Brasília, 22/12/1996a.

- MTb. SEFOR. Educação Profissional: um projeto para o desenvolvimento sustentado. Brasília: Sefor, 1995. 24 p.

. MTE. SPPE. Conhecendo o Planfor: como o Governo Federal e Ministério do Trabalho e Emprego estão Qualificando o Brasil. Brasília: MTE, SPPE, 2001. $23 \mathrm{p}$.

. MTE. SPPE. Plano Nacional de Qualificação - PNQ. Resolução no 333 Codefat. Brasília: MTb, SPPE, 2003. 30 p.

. Decreto 2208, de 17 de Abril de 1997. Diário Oficial [da República

Federativa do Brasil]. Brasília, 1997. Disponível em [http://www.mec.gov.br/semtec/educprof/ttp/dec2208.rtf], acessado em 16/07/2004.

CARDOSO, Fernando H. Avança Brasil: mais quatro anos de desenvolvimento para todos - proposta de governo. Brasília (DF): s/ed., 1998. 332 p. 


\section{Trabalhonecessário}

Issn: 1808 - 799X

ano 11, no $16-2013$

. Mãos à Obra Brasil: proposta de governo. São Paulo: s/ed., 1994. 300

p.

CASTILLO, Noela Invernizzi. Alguns questionamentos sobre a hipótese da requalificação do trabalho. Educação e Sociedade, Jul 1997, vol. 18, № 58, p.5483.

CÊA, Georgia S. S. Educação Profissional sob a Ótica da Mediação e da Ruptura: reflexões sobre o Planfor. Trabalho \& Crítica - GT Trabalho e Educação da ANPEd, № 02, pp. 93-104, set./2000.

COUTINHO, Carlos Nelson. Contra a Corrente: ensaios sobre democracia e socialismo. São Paulo: Cortez, 2000.176 p.

. Democracia e Socialismo. São Paulo: Cortes, 1992.

. Marxismo e Política: a dualidade de poderes e outros ensaios. São Paulo: Cortez, 1994. 160 p.

DELUIZ, Neise; SANTANA, Marco A. \& SOUZA, Donalldo B. Trabalho e Educação: centrais sindicais e reestruturação produtiva no Brasil. Rio de Janeiro: Quartet, 1999. 196 p.

FIDALGO, Fernando. A Formação Profissional Negociada: França e Brasil, anos 90. São Paulo: Anita Garibaldi, 1999. 226 p.

FOGAÇA, Azuete. Educação e qualificação profissional nos anos 90: o discurso e o fato. In: OLIVEIRA, Dalila. A. \& DUARTE, M. R. T. Política e Trabalho na Escola: administração dos sistemas públicos de educação básica. Belo Horizonte: Autêntica, 1999. p. 55-58.

GONZALO, G. Políticas de Empleo, Formación y Diálogo Social: discusión conceptual y aproximación empírica al caso uruguayo. Montevideo: CINTERFOR, 2002. 96 p.

GRAMSCI, Antonio. Cadernos do Cárcere. Tradução de Carlos Nelson Coutinho. Rio de Janeiro: Civilização Brasileira, 1999. Vol I: Introdução ao estudo de filosofia. A filosofia de Benedetto Corce (494 p.). 


\section{Trabalhonecessário}

Issn: 1808 - 799X

ano 11, no $16-2013$

- Cadernos do Cárcere. Tradução de Luiz Sérgio Henriques, Marco Aurélio Nogueira e Carlos Nelson Coutinho. Rio de Janeiro: Civilização Brasileira, 2000. Vol II: Maquiavel. Notas sobre o Estado e a Política (428 p.).

Cadernos do Cárcere - Temas de cultura. Ação Católica. Americanismo e fordismo. Traduzido por Carlos Nelson Coutinho \& Luiz Sérgio Henriques. Rio de Janeiro: Civilização Brasileira, 2001. Vol. IV [394 p.].

KUENZER, Acácia Z. Ensino Médio e Profissional as Políticas do Estado Neoliberal. São Paulo: Cortez, 1997. 104 p.

MACHADO, Lucília R. S. Politecnia, Escola Unitária e Trabalho. (2 Edição). São Paulo: Cortez, 1991. 271 p.

MANACORDA, Mário Alighiero. Marx e a Pedagogia Moderna. Tradução de Newton Ramos de Oliveira. São Paulo: Cortez: Autores Associados, 1991. 221 p. MANFREDI, Silvia Maria. Educação Profissional no Brasil. São Paulo: Cortez, 2002.

MARX, Karl; ENGELS, Frederick. Manifesto Del Partido Comunista / Critica Del programa de Gotha. México (D.F.): Roca, 1972. 155 p.

MILITÃO, Mán. Nair A. Flexibilização da Educação Profissional. Trabalho \& Educação - Revista do NETE, № 03, pp. 95-105, jan./jul., 1998.

MORAES, Carmem Sylvia V. A Reforma do Ensino Médio e a Educação Profissional. Trabalho \& Educação - Revista do NETE, №03, pp. 107-117, jan./jul., 1998.

NEVES, Lúcia M. W. Educação e Política no Brasil de Hoje. 2a Edição. São Paulo: Cortez, 1994. 120 p.

NOGUEIRA, Maria Alice. Educação, Saber, Produção em Marx e Engels. $2^{a}$ Edição. São Paulo: Cortez, 1993. 220 p.

OLIVEIRA, M. A. M. A Reforma do Ensino Profissional: desmantelamento da educação tecnológica ministrada pelo CEFET-X. In: Reunião Anual da ANPEd, 


\section{Trabalhonecessário}

Issn: 1808 - 799X

ano 11, no $16-2013$

XXIV, Out./2001, Caxambu(MG). Anais da XXIV Reunião Anual da ANPEd. Caxambu(MG): Microservice Microfilmagens e Reproduções, 2001. CD-ROM.

OLIVEIRA, R. Ensino Médio e Educação Profissional - reformas excludentes. In: Reunião Anual da ANPEd, XXIV, Out./2001, Caxambu(MG). Anais da XXIV Reunião Anual da ANPEd. Caxambu(MG): Microservice Microfilmagens e Reproduções, 2001. CD-ROM.

PORTELLI, H. Gramsci e o Bloco Histórico. Rio de Janeiro: Paz e Terra, 1997. $142 \mathrm{p}$.

SANTOS, Aparecida F. Tiradentes. O Novo Ensino Médio Agora é para a Vida: neoliberalismo, racionalidade instrumental e a relação trabalho-educação na reforma do ensino secundário. In: Reunião Anual da ANPEd, XXIV, Out./2001, Caxambu(MG). Anais da XXIV Reunião Anual da ANPEd. Caxambu(MG): Microservice Microfilmagens e Reproduções, 2001. CD-ROM.

SANZ, Y. P. La Formación Continua en España. In: Seminário Internacional Emprego e Desenvolvimento Tecnológico, 12 - 18/11/1997, São Paulo. Paper da Conferência “La formación continua en España”. São Paulo: 1997. [mimeo] 10 p.

SCHULTZ, T. W. O Capital Humano: investimentos em educação e pesquisa. Rio de Janeiro: Zahar, 1973. 250 p.

SOUZA, José dos Santos. Concepções e Propostas da CUT e da Força Sindical para a Educação Brasileira - Anos 90. In: NEVES, L. M. W. (Org.). Educação e Política no Limiar do Século XXI. Campinas (SP): Autores Associados, 2000. Cap. III, pp. 79-102.

Trabalho, Educação e Sindicalismo no Brasil - anos 90. Campinas (SP): Autores Associados, 2002. 223 p.

TUMOLO, Paulo Sérgio. A Cut e a formação profissional: esboço de análise crítica. Trabalho \& Crítica - GT Trabalho e Educação da ANPEd, № 01, pp. 98112, Set./1999.

TrabalhoNecessário - www.uff.br/trabalhonecessario; Ano 11, № 16/2013. 


\section{Trabalhonecessário}

Issn: $1808-799 X$

ano 11, no $16-2013$

Data de recebimento: 26/01/2013

Data de aprovação: 25/02/2013 